\title{
Alfred Ramos (2015): Mestres de la impremta. El moviment Freinet Valencià (1931-1939), Castelló de la Plana, Universitat Jaume I; Francesca Vidal Bellés (2014): Antoni Porcar i Candel. El mestre que va donar la paraula als infants (1904- 1947), Castelló de la Plana, Universitat Jaume I.
}

Ambdues recerques que comento tenen punts de coincidència en tractar el mateix objecte d'estudi. L'única diferència és que Ramos analitza sistemàticament l'articulació freinetista valenciana i Vidal en concentra la trajectòria en la biografia del mestre Antoni Porcar.

Mestres de la impremta és una recerca capdavantera a l'hora d'analitzar l'evolució organitzativa de I'Escola Nova Valenciana sota la influència de Celéstine Freinet (1896-1966). L'autor organitza la recerca a partir de l'aportació del pedagog comunista francés, sistematitza la influència que les seves idees tingueren en els precursors intel-lectuals regeneracionistes krausistes -el mestre Fèlix Martí Alpera (1875-1946)- $i$ en els protagonistes pedagogs valencians en el marc republicà, i acaba per resseguir-ne el fil sota la repressió -els expedients de depuració- francofalangista. L'estudi detalla la dedicació -i la geografia pedagògica- dels setanta-nou mestres adscrits a la renovació cooperativista que tingué en l'edició de revistes escolars una expressió reeixida. I allò més important: el lector accedeix a l'esperit cultural que vehiculava la voluntat formativa fonamentada en l'ajut mutu -concebut com a comunitatde professorat i alumnat.

Dos aspectes rellevants plantejats estructuradament en aquesta obra -que, sens dubte, caldria desenvolupar en posteriors recerques autònomes- són, d'una banda, l'anàlisi de les quaranta-una publicacions escolars valencianes sorgides de la impremta escolar cooperativa -objectiu plantejat a l'epígraf 'Una poderosa xarxa de relacions i d'intercanvis' (pp. 202-389)-, que permet conèixer l'intercanvi amb publicacions anàlogues de la resta dels Països Catalans -especialment amb la revista penedesenca Avant (1936). Per altra costat, l'estudi de la configuració de la pedagogia valencianista que, molt encertadament, l'autor situa des de l'acció nacionalitzadora de l'associació València Nova (1907) fins a la funció alfabetitzadora de la Protectora de l'Ensenyança Valenciana (1934), translació interregional de la Protectora de l'Ensenyança Catalana (1899).

Aquests aspectes apuntats facilitarien, encara més, el coneixement de la tasca dels mestres valencians amb pràctica didàctica d'orientació nacional -com seria la necessària biografia de Francesc Boix Senmartí- vinculada a la concepció cultural modernitzadora de la Mancomunitat -Eladi Homs, els Quaderns de Pedagogia (1915-1914) i el Butlletí dels Mestres (1922-1938)- i al programa renovador de les Escoles d'Estiu de Barcelona (1932 i 1933). Aquesta influència és rellevant perquè -com exposa Ramos- es troba reflectida en l'organització de la I Colònia Escolar Valencianista de Sant Pau d'Albocàsser (1933) (pp. 90-102). No en va, el primer Estatge dels mestres valencianistes dels anys seixanta -com a acte de memòria pedagògica- hi tingué lloc (1967).

La biografia civicointel.lectual del mestre castellonenc Antoni Porcar i Candel-exposada rigorosament per Francesca Vidal a través de documentació original i d'històries orals evocades per alumnes d'aquest professor- explica la seva trajectòria en els centres escolars de la Plana Alta, Alt Urgell i Baix Maestrat, la recepció que feu, entre d'altres, de les idees de l'intelllectual Alexandre Galí, la relació amb 
I'avantguarda freinetista del Grup Batec (1931) i la participació en la política educativa de la Generalitat Republicana -a través de cursos d'especialització (1933).

Aquesta evolució explica com, per exemple, sota el mestratge de Porcar, els alumnes de Canet Lo Roig editessin la revista Ibèria (1934-1935) -a través de la qual es pot comprendre el sentit d'alguns textos evocatius dels xiquets canetins com fou la del polític Francesc Macià-, i que dos anys després el grup escolar de Vinaròs publiqués la revista Gavina (1936). Tot plegat ratifica la influència que tingué en Porcar la relació mantinguda amb nuclis intel-lectuals castellonencs, cosa que el dugué a l'adscripció al valencianisme republicà d'esquerres.

El treball sobre els mestres freinetistes valencians dut a terme per Alfred Ramos i la biografia de Vidal Bellés referent al 'mestre de la impremta' Antoni Porcar i Candel suposen una fita historiogràfica. Aporten claus interpretatives per a comprendre perquè els joves mestres de la Secció Pedagògica del Rat Penat, encapçalats per Ferran Zurriaga Agustí, incorporaren el treball cooperatiu de Freinet a la dedicació educativa, connectaren amb referents pedagògics dels anys trenta -Enric Soler i Godes- editaren la revista fonamental Escola, establiren relacions amb el moviment de renovació pedagògica del Principat i en potenciaren el projecte als anys setanta. Aquesta activitat serví -i serveix-d'alçaprem per a les noves baules generacionals d'estudiosos $i$ ensenyants que encara creuen en la pràctica pedagògica autogestionada com a motor d'intel.ligència $i$, en conseqüència, posen en dubte l'enfocament tecnocràtic actual de l'educació. El moviment 'Escola Valenciana' no ha sorgit del no res.

Xavier Ferré Trill. Departament de Pedagogia. Universitat Rovira i Virgili

xavier.ferre@urv.cat 